\title{
Special Issue on the Life and Work of Donald Capps (1939-2015)
}

\section{Robert C. Dykstra' ${ }^{1}$ Nathan Carlin ${ }^{2}$}

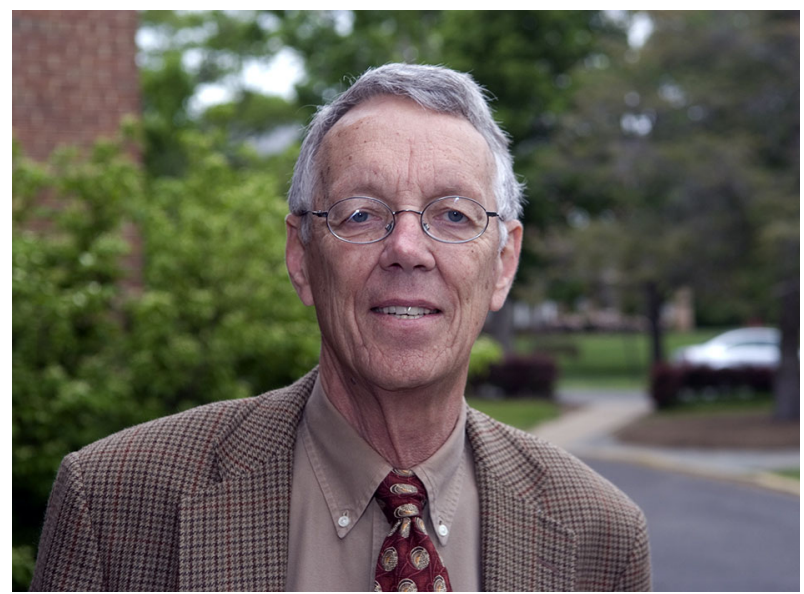

The photograph of Donald Capps is courtesy of Princeton Theological Seminary (photo credit C. Nolan Huizenga).

When Curtis Hart, editor of the Journal of Religion and Health, graciously invited the two of us to serve as guest editors for the present volume in honor of Donald Capps, we quickly jumped at the chance. Capps, our mentor and friend, died suddenly on August 26, 2015, at

Robert C. Dykstra

robert.dykstra@ptsem.edu

Nathan Carlin

Nathan.Carlin@uth.tmc.edu

1 Princeton Theological Seminary, P.O. Box 821, Princeton, NJ 08543-0802, USA

2 McGovern Medical School, 6431 Fannin Street, JJL 410, Houston, TX 77030, USA 
age 76, from injuries sustained in an automobile accident near his home in Princeton. A pivotal influence in our own lives and vocational trajectories, he was the most prolific pastoral theologian in the history of the modern discipline.

Capps's global reach in the fields of psychology of religion and pastoral theology is evident in his more than forty published books and hundreds of articles (see Dykstra and Cole 2009, pp. 681-693; Dykstra and Carlin 2016b, pp. 717-721), in his teaching over four decades at Princeton Theological Seminary and elsewhere, and in an unceasing stream of personal correspondence offering encouragement to friends and former students through letters and email. But he wore this renown lightly. Those who knew him will remember not only the range and precision of his beautiful mind but also the unremitting attention he paid to the unique interests and concerns of each individual in his care.

In a memorial essay published shortly after his death, we (Dykstra and Carlin 2016a, pp. 571-586) focused on key biographical markers from Capps's childhood onward that contributed to interests, such as those of the origins and assuagement of male melancholia or of the importance of attending to the individual, central to his scholarly pursuits. The present volume, through consideration of Capps's various key writings and thematic interests, focuses less on his personal life story than on the vast scope of his intellectual achievements. In our effort to demonstrate this expansiveness, we have invited diverse scholars from the USA, Canada, the Netherlands, South Africa, and South Korea-each of whom knew Capps on a personal basis - to reflect and then, drawing from their own areas of expertise, to build on various of Capps's writings around a specific theme.

Themes of recurring interest to Capps examined in this volume include: the ages and seasons of life (Zock); the child and the child within (Hinds); the Bible in pastoral care (Dreyer); male melancholia and the psychology of religion (Shin); psychobiography (Jacobs); pastoral care and counseling (LaMothe); pastoral care for those suffering mental and emotional disorders (Carlin); the place of poetry and art in pastoral care (Zylla); the role of humor in healing (Lee); and the self and the importance of the individual (Abraham). We realize that this list of themes and certainly the number of Capps's written works addressed in these pages are in no way exhaustive. But the articles that follow do succeed in demonstrating, individually and collectively, not only the encyclopedic nature of Capps's own mind but also the playful generativity he inspired and promoted in the scholarly pursuits of countless students and colleagues.

In "Human Development and Pastoral Care in a Postmodern Age: Donald Capps, Erik H. Erikson, and Beyond," Hetty Zock expertly traces Capps's lifelong appropriation of the developmental psychology of Erik H. Erikson for informing pastoral and, in Zock's increasingly secular Dutch context, spiritual care. She posits that Capps eventually abandoned the idea that his models of pastoral care required expressly biblical underpinnings, as he increasingly felt free to draw from all manner-literary, artistic, poetic, phenomenological—of postmodern disciplinary sources.

In his poignant “The Son's Fault: Martin Luther King Jr.'s Search for and Recovery of Sonship," Jay-Paul Hinds draws on Capps's emphasizing the importance for a boy or young man to find alternative father-figures who can affirm the value of viewing himself as a son, not just as a man - that is, who allows him to regress responsibly to sonshipthroughout his entire life course. Through psychoanalytic psychobiography, Hinds applies Capps's insight by finding a "fault-line," stemming from unresolved experiences of childhood abuse at the hands of his father, that haunted the psychospiritual development of Martin Luther King, Jr.

Yolanda Dreyer nominates some philosophical and theological forerunners-Johann Gottfried von Herder, Friedrich Schleiermacher, William James, and Paul Ricoeur-to 
Capps's appropriation of the Jesus-narrative for reframing human brokenness and for healing a deep sense of shame, depersonalization, and self-depletion that characterize widespread contemporary narcissism. She succinctly captures the heart of Capps's claim for the religious enterprise, one of restoring a sense of wholeness to the individual who suffers from self-loathing, especially by means of making peace with the child one once was and by reclaiming inner agency.

Through groundbreaking consideration of etymological roots of the Chinese character for han-often perceived by scholars as "the most prominent emotional characteristic of Koreans' psychological experience"-and by drawing on Capps's writings on male melancholia, Hyon-Uk Shin, in "Melancholy, Acculturation, and Relief: A Brief Essay on the Religion of Ordinarity," asserts that han extends to the experience of persons in a far broader contingent of cultures. He describes han as a complex form of melancholy deriving from impairment of individual agency amid systemic absurdities or cultural oppression, phenomena not at all exclusive to Korean society. The extraordinary circumstances that give rise to han, he proffers, might helpfully press individuals to seek ordinary forms of religious expression, a calming "religion of ordinarity," as avenues of relief.

In "Psychobiography and the Psychology of Religion: A Tribute to the Work of Donald Capps," Janet Jacobs offers a close and compelling post-colonial reading of four of Capps's books on psychobiography. She traces, in part, how Capps's original psychohistorical interpretations of the "utopian-melancholic" personality of Jesus of Nazareth render him more human and therapeutically accessible. Capps, for Jacobs, "fundamentally changed the way in which we approach and appreciate the role of psychology in the study of religion and religious figures."

In addition to his contributions as a psychologist of religion, Capps was a teacher who sought to guide seminarians in offering counsel to those in need. Ryan LaMothe, in "Giving Counsel: Donald Capps' Contributions to Pastoral Counseling," deftly coaxes from Capps's works certain key attributes useful for ministers who counsel in congregational settings. Capps believed it was important for ministers to actually help parishioners solve problems, especially by reframing their stories, cognitively and emotionally, through multiple possible interpretive frameworks. LaMothe recognizes that Capps's own personal qualities of curiosity, kindness, and judiciousness can serve to enhance the ability of other ministers, even as non-experts, to provide life-giving counsel.

In "Reflections for Clinical Pastoral Education Students in Psychiatric Settings," Nathan Carlin draws from years of ministry among psychiatric patients, and from insights and lessons derived from several of Capps's books on mental illness, to offer guidance for those charged with leading worship services in psychiatric institutions. He notes how, for Capps, familial and communal support contributes to the well-being of persons with mental illness; how mental illness presents not only real challenges to, but opportunities for creativity and growth in, patients and their loved ones; and how the act of reading, especially reading works written by those who have suffered their own or a family member's mental illness, is therapeutic in its own right. These insights lead Carlin to shape worshipful encounters in psychiatric settings in rich and nuanced ways.

Phil Zylla, in his insightful "Explorations in the Aesthetic Pastoral Theology of Donald E. Capps," finds it entirely fitting that at the time of his death Capps was working on a new book on pastoral perception. "The curative effects of art," Zylla discerns, were paramount not only in the lives of two major psychologists, William James and Erik Erikson, of enduring importance to Capps, but in Capps's own life as well. He "looked at things" through the eyes of an artist. He expressed in numerous essays and books how studying 
works of art and artists can illumine pastoral ministry, specifically in ways that great art reframes human perceptions and enhances embodied freedom.

Sang Uk Lee, in his engaging "Humor as Wisdom for Reframing Life," draws both from some funny personal memories as a doctoral student of Capps and from a number of Capps's books on the therapeutic value of humor to claim that older adults have much to teach younger adults about managing existential anxiety. Older adults, Lee asserts, are more likely to have developed the wisdom that allows them to hold in tension competing points of view. Their humor shows that the world need not function in tidy or systematic ways and encourages us to find the "noble" in everyday life.

Reggie Abraham, in "Revisiting The Depleted Self," returns to Capps's influential book on the ubiquity of the narcissistic self in contemporary culture. He persuasively demonstrates the book's continuing relevance even several decades after its publication. In The Depleted Self (Capps 1993), Capps points to a growing sense of sin not as an experience of inner guilt, of having done something wrong, but rather as a sense of pervasive shame, of somehow being wrong, in the self-experience of modern persons. Abraham discerns that this core belief contributed to Capps's shunning of moralistic prescription and bureaucratic hierarchies in his approach to pastoral care, leading him instead to favor psychodynamic sensitivities and a gracious acceptance of individuals.

Finally, in a fitting concluding sermon tribute to Capps, "Jesus the Healer: A Sermon in Honor of the Memory of Donald Eric Capps (1939-2015)," Donald R. Ferrell, a former editor of the Journal of Religion and Health, introduces his congregation to Capps's surprising claims, in Jesus the Village Psychiatrist (Capps 2008), concerning Jesus' healing ministry. Focusing particularly on the gospel account of Jesus healing the blind beggar Bartimaeus (Mk. 10:46-52), Ferrell affirms, with Capps, that Jesus resolutely seeks to help his followers to live without fear, to face our wounds, to live with passion, courage, and compassion-qualities that many of the authors of the essays of this volume, along with countless others of his former students, colleagues, and readers near and far, would attest to as ably capturing the character and life of our beloved friend and hero, Donald Capps.

\section{References}

Capps, D. (1993). The depleted self: Sin in a narcissistic age. Minneapolis, MN: Fortress Press.

Capps, D. (2008). Jesus the village psychiatrist. Louisville, KY: Westminster John Knox.

Dykstra, R. C., \& Carlin, N. (2016a). At home in the world: A memorial tribute to Donald Capps (1939-2015). Pastoral Psychology, 65, 571-586.

Dykstra, R. C., \& Carlin, N. (2016b). Books and articles by Donald Capps, 2009-2016. Pastoral Psychology, 65, 717-721.

Dykstra, R. C., \& Cole, A. H., Jr. (2009). Books and articles by Donald Capps. Pastoral Psychology, 58, 681-693. 